\title{
Endoscopic Treatment for Vesicoureteral Reflux in Recurrent Urinary Tract Infections in Kidney Transplant: Experience of One Center(Article)
}

- Gomez Lujan, M.abEmail Author,

- Velarde, L.',

- Cruzalegui, C. ${ }^{a}$,

- Berrios, C.a,

- Sifuentes, E.a,

- Gálvez, J.a,

- Soto, H.a,

- Castañeda, E. ${ }^{a}$,

- Bazán, G. a,

- Nakachi, A.a,

- Chambi, M.a,

- Medina, C.a,

- Torres, A. ${ }^{a}$

- View Correspondence (jump link)

- aDepartment of Nephrology, Edgardo Rebagliati Martins National Hospital, EsSalud, Lima, Peru

- 'Escuela de Medicina, Universidad Peruana de Ciencias Aplicadas, Lima, Peru

- 'Department of Urology, Edgardo Rebagliati Martins National Hospital, Lima, Peru

\begin{abstract}
View references (6)
Vesicoureteral reflux (VUR) after renal transplantation in adult patients has been reported. In renal transplant recipients, symptomatic urinary tract infection can cause high morbidity despite improved immunosuppressive and antibiotic treatment. In our country there have been few reported cases about use of copolymer of dextranomer and hyaluronic acid (DX-HA) injection in a renal transplant. We present 3 cases of recurrent or complicated infections with evidence of high-grade VUR, which were treated with DX-HA. Only 1 case had a partial remission; however, there were no episodes of urinary tract infection in 12 months of follow-up. Suburethral injection is an endoscopic treatment modality with low morbidity in our country. (C 2018 Elsevier Inc.
\end{abstract}

- ISSN: 00411345

- CODEN: TRPPA

- Source Type: Journal

- Original language: English

- DOI: 10.1016/j.transproceed.2018.01.007

- Document Type: Article 
- Publisher: Elsevier USA 
